\section{CATASTROPHIC COMPLICATIONS OF THE CERVICAL ESOPHAGOGASTRIC ANASTOMOSIS}

Recent enthusiasm for the cervical esophagogastric anastomosis has arisen because of its perceived low morbidity. Although catastrophic complications of a cervical esophagogastric anastomosis are unusual, they can and do occur, and prevention is possible if the potential for them is recognized. Among 856 patients undergoing a cervical esophagogastric anastomosis after transhiatal esophagectomy, catastrophic cervical infectious complications occurred in 11 patients $(1.3 \%)$ : vertebral body osteomyelitis (1), epidural abscess with neurologic impairment (2), pulmonary microabscesses from internal jugular vein abscess (1), tracheoesophagogastric anastomotic fistula (1), and major dehiscence necessitating anastomotic takedown (6). These complications became manifest from 5 to 85 days after the esophageal resection and reconstruction (mean 19 days). Leakage from a gastric suspension stitch placed in the anterior spinal ligament over the vertebral bodies resulted in a posterior gastric leak and either osteomyelitis or an epidural abscess in three patients, none of whom had evidence of extravasation on the routine barium swallow 10 days after operation. Cervical exploration for a presumed anastomotic leak led to the unexpected discovery of an abscess formed by the stomach and the adjacent wall of the internal jugular vein, which was ligated and resected. One patient without symptoms who was discharged from the hospital with a contained anastomotic leak on the postoperative barium swallow was readmitted 7 days later with a cervical tracheoesophagogastric anastomotic fistula of which he ultimately died. In 6 patients (7\% of those who had anastomotic leaks) there was sufficient gastric ischemia or necrosis, or both, to necessitate takedown of the anastomosis and intrathoracic stomach, cervical esophagostomy, and insertion of a feeding tube. As a result of this experience, it is recommended that cervical gastric suspension sutures either be omitted entirely or placed in the fascia over the longus colli muscles anterior to the spine, but not directly into the prevertebral fascia overlying the vertebral bodies or cervical disks. All but minute cervical anastomotic leaks, even if apparently contained, are best drained rather than treated expectantly. Patients who remain febrile and ill after bedside drainage of a cervical esophagogastric anastomosis leak should undergo cervical reexploration in the operating room; major gastric ischemia or necrosis, or both, may warrant takedown of the anastomosis and intrathoracic stomach. (J THORAC CARDIOVASC SURG 1995;110:1493-1501)

Mark D. Iannettoni, MD (by invitation), Richard I. Whyte, MD (by invitation), and Mark B. Orringer, MD, Ann Arbor, Mich.
From the Section of Thoracic Surgery, Department of Surgery, The University of Michigan Medical Center, Ann Arbor, Mich.

Read at the Seventy-fifth Annual Meeting of The American Association for Thoracic Surgery, Boston, Mass., April 23-26, 1995.

Address for reprints: Mark D. Iannettoni, MD, Section of Thoracic Surgery, University of Michigan Medical Center, 1500 E. Medical Center Dr., 2120 Taubman Center, Box 0344, Ann Arbor, MI 48109-0344.

Copyright (C) 1995 by Mosby-Year Book, Inc.

$0022-5223 / 95 \$ 5.00+0 \quad \mathbf{1 2 / 6 / 6 8 1 0 5}$
$\mathrm{D}$ uring the past two decades, the cervical esophagogastric anastomosis (CEGA) after esophagectomy has gained increased popularity. In our experience, the morbidity of a CEGA leak is essentially a transient cervical salivary fistula, whereas morbid sequelae of an intrathoracic anastomotic disruption are mediastinitis and sepsis, which are often fatal. ${ }^{1-11}$ Although the morbidity and mortality of esophageal resection and reconstruction have been greatly decreased by use of a CEGA, this anastomosis is not without its complications, and relatively 
Table I. Major complications of CEGA

\begin{tabular}{|c|c|c|c|c|}
\hline $\begin{array}{l}\text { Patient } \\
\text { No. }\end{array}$ & Age/sex & $\begin{array}{l}\text { Esophageal } \\
\text { pathologic } \\
\text { condition }\end{array}$ & Complications/POD & Suspected cause \\
\hline 1 & $65 / \mathrm{M}$ & Barrett's mucosa, severe dysplasia & Left IJV abscess/20 & Contained undiagnosed leak \\
\hline 2 & $85 / F$ & Distal adenocarcinoma & Cervical osteomyelitis/85 & Suspension stitch gastric necrosis \\
\hline 3 & $66 / \mathrm{M}$ & Distal adenocarcinoma & Cervical osteomyelitis with quadriplegia/31 & Suspension stitch gastric necrosis \\
\hline 4 & $59 / \mathrm{M}$ & Distal adenocarcinoma & Cervical osteomyelitis with quadriplegia/11 & Suspension stitch gastric necrosis \\
\hline 5 & $63 / \mathrm{M}$ & Distal adenocarcinoma & $\mathrm{TEF} / 19$ & Contained undrained leak \\
\hline 6 & $57 / \mathrm{M}$ & Megaesophagus & Gastric tip necrosis $/ 8$ & Hypotension \\
\hline 7 & $73 / \mathrm{M}$ & Discontinuity, prior exclusion & Gastric tip necrosis $/ 10$ & Chronic steroid use \\
\hline 8 & $25 / \mathrm{M}$ & Mid one third radiation, stricture & Gastric tip necrosis/5 & RGEA divided previously \\
\hline 9 & $60 / \mathrm{M}$ & Distal adenocarcinoma & Gastric tip necrosis/6 & Hypotension \\
\hline 10 & $63 / \mathrm{M}$ & Distal adenocarcinoma & Gastric tip necrosis/7 & Hypotension \\
\hline 11 & $67 / \mathrm{F}$ & Mid one third adenocarcinoma & Gastric tip necrosis $/ 10$ & $\begin{array}{l}\text { Gastric compression at thoracic } \\
\text { inlet }\end{array}$ \\
\hline
\end{tabular}

POD, Postoperative day; $B a S$, barium swallow; $M$, male; $I V$, internal jugular vein; $I V$, intravenous; $A / W$, alive and well; $F$, female; $T E F$, tracheoesophageal fistula; $A R D S$, acute respiratory distress syndrome; $C E G$, cervical esophagostomy; $R E G A$, right gastroepiploic artery; $M S O F$, multisystem organ failure.

minor alterations in operative technique can minimize these problems resulting in improved immediate and long-term results. Although the majority of CEGA leaks are relatively small and can be managed at the bedside by simply opening the neck wound and initiating wound irrigation and packing, major disruptions of the anastomosis may result in a serious cervical or superior mediastinal abscess or such a large leak that local wound care is inadequate to control the problem. ${ }^{12}$ In our experience with more than 850 transhiatal esophagectomies (THEs) with CEGAs, several life-threatening complications of cervical anastomotic disruption have been encountered and have resulted in modification of our operative technique to prevent recurrence of these catastrophic problems.

\section{Patients}

Since 1976, 911 THEs with 903 CEGAs have been done by the University of Michigan Thoracic Surgery Service. In 856 patients (94\%), stomach was used as the esophageal substitute, and colon was used in $45(5 \%)$. Retrosternal esophagogastric anastomoses were constructed in 14 ( $2 \%)$ of these patients, who are excluded from this analysis. In 842 patients (98\%) the stomach was positioned in the posterior mediastinum in the original esophageal bed and a CEGA was done, and these patients form the basis of this report. From these latter patients, the University of Michigan Thoracic Surgery Esophageal Resection and Reconstruction Database identified 88 (10.4\%) who had an early postoperative cervical "leak," generally at the anastomosis (74 patients, 9\%) or at what was believed to be the site of suspension of the gastric fundus from the cervical prevertebral fascia (14 patients, $2 \%$ ). Of these 88 patients, $11(1.3 \%)$ had major complications defined as those not managed successfully by simple opening of the neck wound and packing. These patients are the subject of this report (Table I).
Patient demographics. Nine of these patients were men and two were women, and they ranged in age from 25 to 85 years (average 61 years). Seven underwent THE because of malignant disease: six had distal esophageal adenocarcinoma (stage I in 1, stage III in 4, and stage IV in 1) and one had midthoracic stage IV adenocarcinoma. The four patients with benign disease underwent esophagectomy because of a nondilatable radiation stricture with Barrett's mucosa (1), an undilatable reflux stricture with severe dysplasia in Barrett's mucosa (1), megaesophagus of achalasia (1), and esophageal discontinuity after exclusion because of a perforation (1).

\section{Results}

Complications. Six patients had necrosis of the tip of the gastric tube resulting in major anastomotic dehiscence. All of these patients had fever, drainage from the lower end of the cervical incision, and a characteristic odor associated with necrotic stomach noticeable on the breath and from the neck wound drainage. When there was no question about the presence of a CEGA leak, the neck wound was opened at the bedside without a prior barium swallow examination. When there was another possible explanation for postoperative fever and a leak was not evident clinically, a contrast study of the esophagus was obtained to be certain that an anastomotic leak was not being overlooked. Barium swallows were obtained in four of these patients and confirmed the presence of a major leak in two (Fig. 1). In contrast to results with a typical CEGA leak, after the neck wound was opened and irrigation and packing was initiated in these patients, the patients' conditions remained toxic and large amounts of swallowed liquids and saliva drained from the wounds. These patients were returned to the oper- 


\begin{tabular}{llll}
\hline $\begin{array}{c}\text { Leak } \\
\text { identified } \\
\text { on BaS }\end{array}$ & Physical findings of leak & & \multicolumn{1}{c}{ Treatment } \\
\hline No & Fever & Drainage, IV antibiotics & Result \\
No & Pain & Discectomy & Died, metastasis, 8 mo \\
No & Pain, fever & Drain epidural abscess, reconstruct anastomosis & Died, metastasis, 6 mo \\
No & Wound drainage & Drain epidural abscess & A/W \\
Yes & None & Close TEF, retrosternal placement of stomach & Died, ARDS, POD 27 \\
Not done & Wound drainage & Take down stomach, CEG & A/W, reconstructed \\
Yes & None & Take down stomach, CEG & Colonic interposition \\
Yes & Fever & Take down stomach, CEG & Jejunal interposition, ARDS, death \\
Yes & Wound drainage & Take down stomach, CEG & Died, metastasis, 21 mo \\
No & Fever, wound drainage & Take down stomach, CEG & Died, MSOF, POD 32 \\
Not done & Wound drainage & Take down stomach, CEG & Died, metastasis, POD 55 \\
& & & \\
\hline
\end{tabular}

ating room between 5 and 10 days (average 7 days) after THE. Exploration of the neck wound revealed gastric necrosis and major anastomotic dehiscence. The upper midline abdominal incision was reopened, the intrathoracic stomach mobilized from the posterior mediastinum through the diaphragmatic hiatus, and the stomach delivered down and out of the chest and into the abdomen. Nonviable stomach was resected with use of the surgical stapler, and a cervical esophagostomy was constructed. Each patient already had a feeding jejunostomy tube, which had been inserted at the initial operation. Of the six patients with major anastomotic disruption, two died of this complication during the hospital stay.

Retrospective review of the records of these six patients was undertaken to identify possible causes for the major anastomotic dehiscence. Three patients had hypotension with low blood flow, which was a direct result of hypovolemia in two. One patient, unbeknownst to the surgeon, received "hypotensive anesthesia" with nitroprusside during the esophagectomy. When the blood pressure of this patient normalized in the intensive care unit after operation, mediastinal bleeding necessitated reoperation, and subsequent hypotension was ultimately followed by major anastomotic disruption. One patient had documented vascular compromise of the stomach at the time of THE as a result of a previously divided right gastroepiploic artery; he had what was believed to be a viable stomach before construction of the CEGA. One patient had residual tumor at the anastomosis on final pathologic analysis. One patient receiving long-term steroid therapy had an uneventful course after THE until a routine barium swallow examination 10 days after operation revealed major anastomotic disruption.

Four patients had anastomotic complications that were not appreciated on the routine barium swallow examination 10 days after operation. In three of these cervical vertebral osteomyelitis developed at the site of suspension of the gastric fundus from the cervical prevertebral fascia; in two of these epidural abscesses developed that necessitated neurosurgical intervertebral disk debridement and drainage (Fig. 2). In these latter two patients quadriplegia occurred, which was permanent in one and required 6 months to resolve in the other. In another patient a contained cervical abscess developed against the left internal jugular vein. This ultimately resulted in intravascularly disseminated pulmonary microabscesses (Fig. 3) and necessitated cervical exploration, ligation and resection of the involved segment of the jugular vein, and long-term intravenous antibiotic therapy.

One patient in our experience had a contained anterior CEGA leak, which was demonstrated on the barium swallow examination 10 days after operation (Fig. 4). This was not drained because the patient was afebrile and free of symptoms. He was readmitted to the hospital 1 week later, however, on postoperative day 19 with coughing and aspiration and required endotracheal intubation and mechanical ventilatory assistance. Bronchoscopy demonstrated a tracheoesophagogastric anastomotic fistula. An attempt was made to repair the fistula and separate the tracheal repair from the esophageal anastomosis with interposed tissue, but this patient eventually died 1 month after operation of multisystem organ failure. 


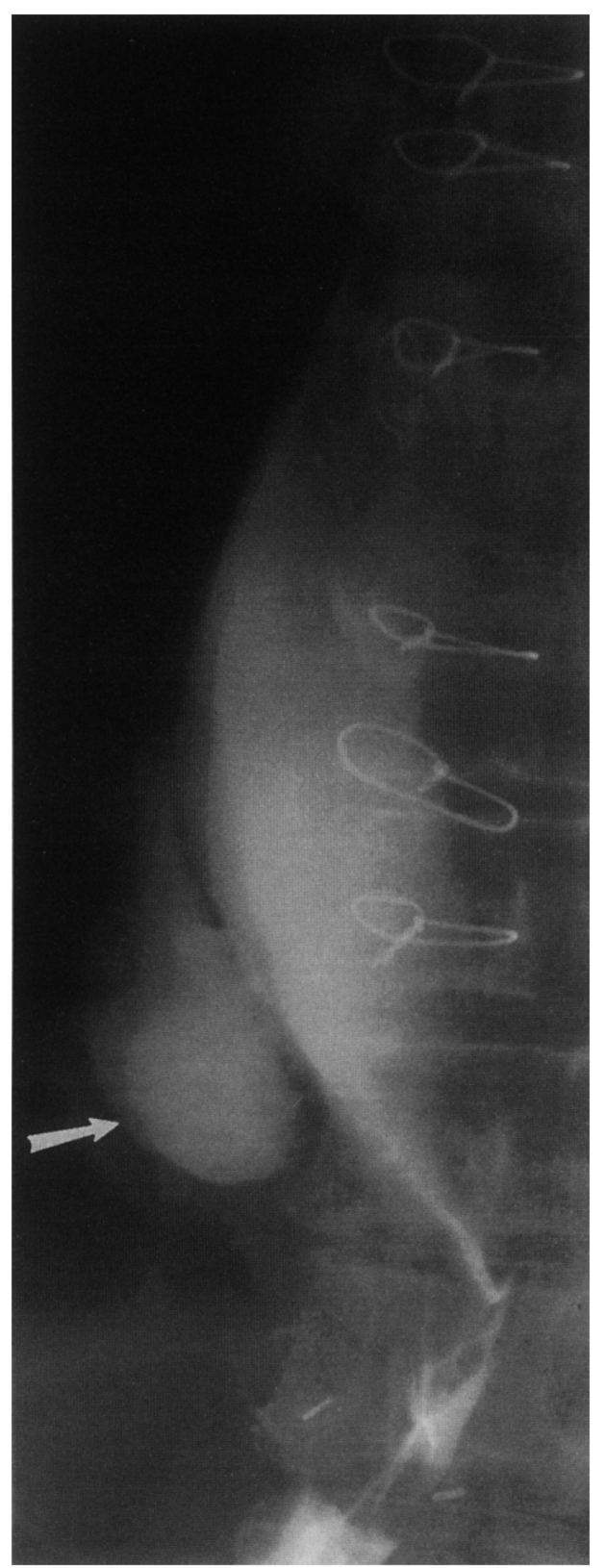

Fig. 1. Barium esophagogram from patient with postoperative fever caused by CEGA disruption associated with gastric tip necrosis. Oblique projection demonstrates extravasation of contrast (arrow) into low posterior mediastinum alongside intrathoracic stomach, indicating major disruption.

Current status. In total, 8 of these 11 patients with major complications of a CEGA survived the complication to leave the hospital. Of the four patients with discontinuity because of gastric tip necrosis, which required takedown of the anastomo- sis, one patient with cancer died of metastatic disease at 21 months, before he was able to undergo reconstruction. The remaining three patients with benign disease underwent operations to reestablish alimentary continuity. One of three patients with benign disease died after later intestinal interposition to reestablish alimentary continuity. Two underwent colonic interposition successfully; one had a jejunal interposition but died of multisystem organ failure after operation. Of the four patients who initially survived delayed complications, two died of metastatic cancer at 6 and 8 months. The other two patients, one with resected cancer and one with benign disease, are doing well at 2 and 6 years, respectively.

\section{Discussion}

As experience is gained with any operation, minor refinements in operative technique can result in significant improvement in results. The change from the intrathoracic anastomosis to the CEGA has resulted in a major reduction in morbidity associated with esophageal anastomotic disruption. The reported prevalence of anastomotic leak after CEGA ranges from $0 \%$ to $39 \%$, but averages approximately $12 \%$ in most recent large series. ${ }^{2,5-7,10,13-19}$ This leak rate remains the Achilles' heel of the operation, because in one third of patients who have an anastomotic leak a subsequent stricture will develop that jeopardizes the long-term functional result of the operation. ${ }^{7}$ It is our belief that the primary reason for the relatively high leak rate associated with a CEGA is the initially compromised blood supply at the apex of the freshly mobilized stomach. This area is most vulnerable to ischemia because it is the farthest from the right gastric and gastroepiploic vessels that nourish the stomach. Compression at the thoracic inlet may further compromise the stomach by producing venous congestion at the apex. As was standard practice in the performance of intrathoracic esophagogastric anastomoses, we have suspended the stomach from the prevertebral fascia in the neck to minimize tension on the anastomosis since our initial description of THE. However, recent experience has shown that the tip of a properly mobilized stomach remains in the neck without the need for suspension sutures, which retrospectively only further compromise an already diminished gastric blood supply near the site of the cervical anastomosis.

Since our initial report of our experience with THE, we have advocated placement of suspension 
sutures between the tip of the mobilized stomach and the cervical prevertebral fascia as a means of minimizing tension on the end-to-side CEGA we do. ${ }^{19,20}$ As this report demonstrates, however, this one relatively minor step may result in major complications and significant morbidity after an otherwise uncomplicated procedure. As originally described, the suspension sutures have been placed through the anterior cervical prevertebral fascia in the midline. ${ }^{21}$ Particularly in elderly patients with cervical vertebral osteophytes, the anterior spinous ligament may be greatly attenuated, and an attempt to suture to it may result in penetration of the underlying disk by the needle and inoculation and subsequent infection by oral bacteria. Alternatively, because the tip of the stomach in the neck is that point at which the blood supply of the recently mobilized stomach is most compromised, placement of suspension sutures may result in focal necrosis at the very tip of the stomach without an associated anastomotic leak.

We have noted in 14 patients this phenomenon of what we believe is such a "suspension stitch necrosis without anastomotic leak." These patients have fever and malodorous cervical drainage after CEGA. When the neck wound is opened at the bedside and the patient given water to drink, no water exits the wound unless the patient is supine or coughs and forcefully expels it from the necrosed suspension stitch site, which is several centimeters cephalad to the anastomosis on the stomach. A barium swallow examination with the patient in the upright position will show no extravasation of contrast unless the patient is tilted head down, which thereby allows barium to fill the tip of the stomach superior to the anastomosis. In these patients the condition typically responds to cervical wound packing for 3 to 5 days, and the fistula closes spontaneously.

In view of our experience with complications of suspension stitches, we no longer place these stitches in the anterior spinal ligament but rather, if we even use them, place them in the fascia overlying the longus colli muscles on either side of the midline. Although this lateral movement prevents the potential neurologic problem associated with disk space infection, it does not eliminate possible focal ischemic necrosis at the suture sites. In our continued effort to minimize further vascular compromise of the mobilized stomach, as advocated by Stone and Heitmiller, ${ }^{22}$ we no longer routinely suspend the stomach posteriorly in the neck. Rather, after completion of the end-to-side CEGA, we now place two

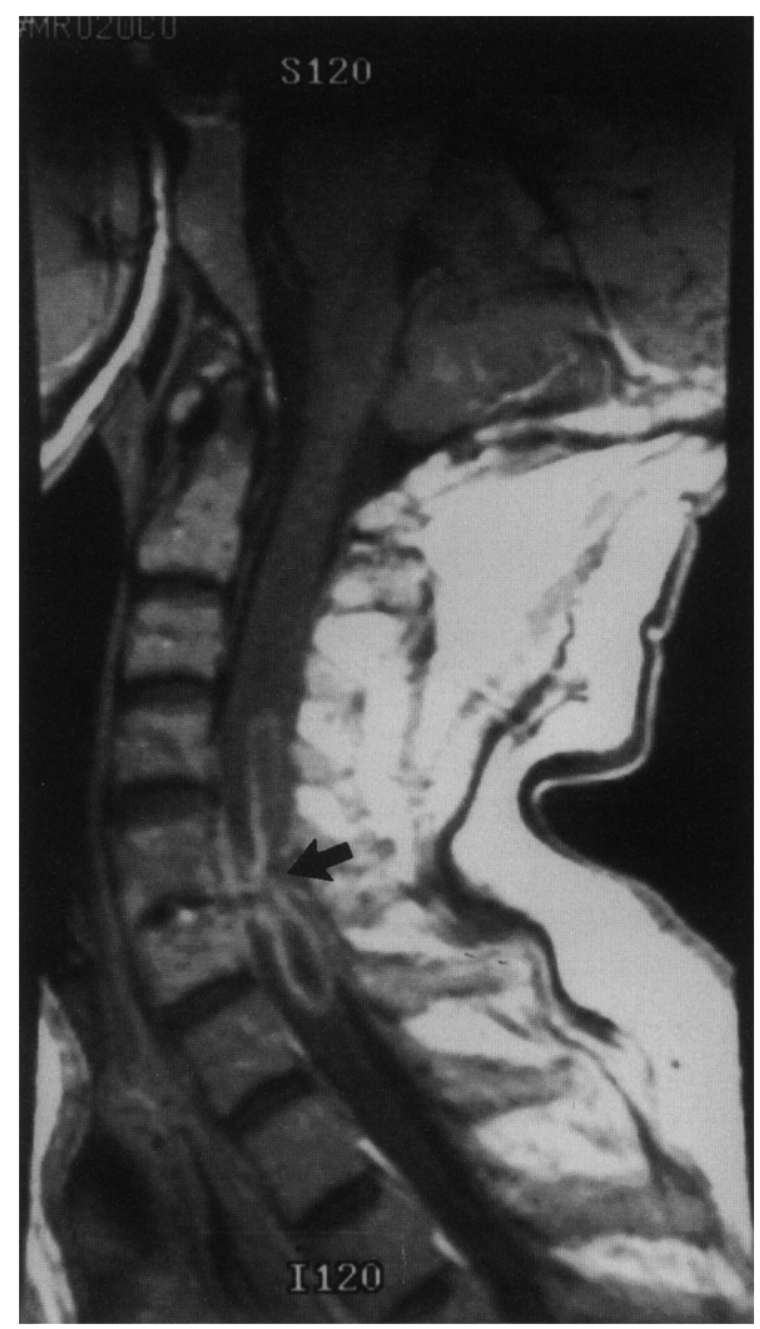

Fig. 2. Cervical magnetic resonance imaging scan of patient 3 who had quadriplegia and neck pain from epidural abscess (arrow) that necessitated operative debridement and drainage.

anterior sutures between the back of the cervical esophagus and the adjacent stomach (Fig. 5). It is yet too soon to determine whether this modification has altered the prevalence of cervical anastomotic wound problems, but in our most recent 22 consecutive CEGA procedures done without a suspension stitch, we have had two leaks.

A major disruption must be suspected in any patient who has had a cervical wound opened and packed as treatment for CEGA leak but remains in febrile and toxic condition after 24 hours. The patient should be returned to the operating room as soon as possible for cervical exploration under optimal surgical conditions. Gastric necrosis should be 


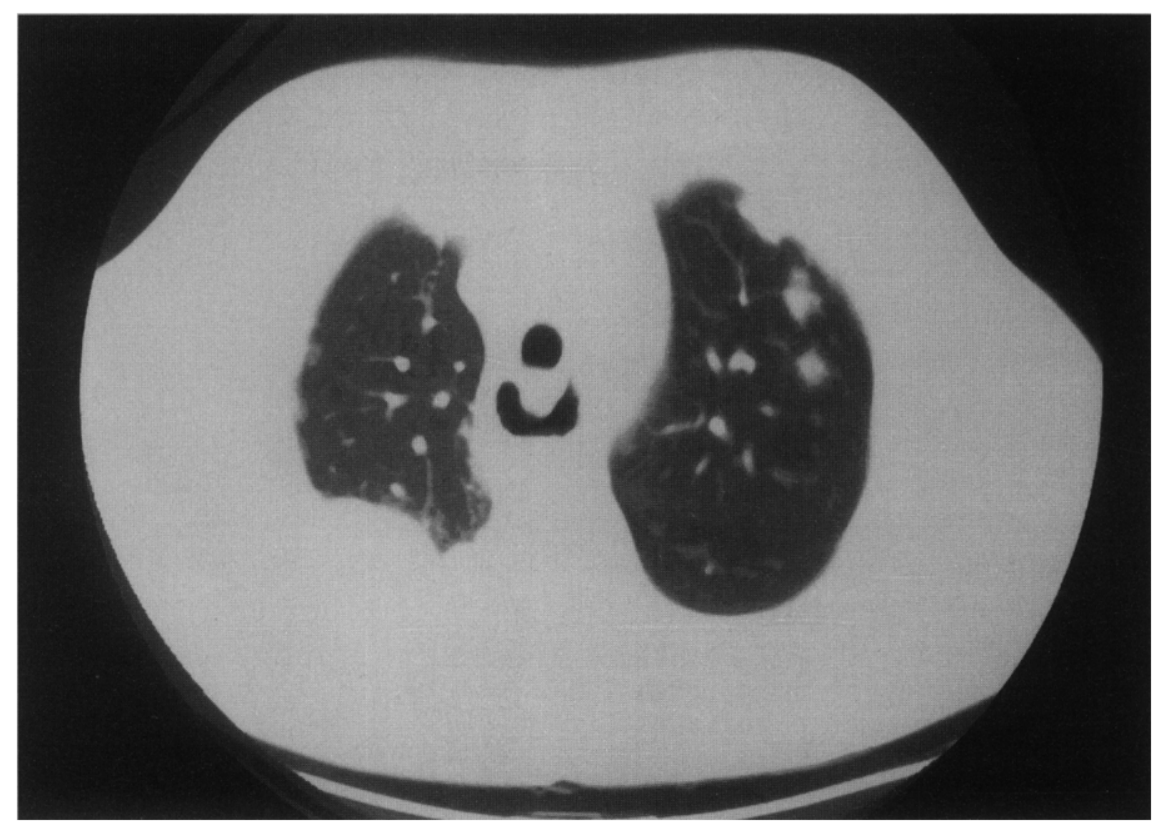

Fig. 3. Chest computed tomographic scan from patient 1 demonstrating multiple pulmonary abscesses as a result of intravascular dissemination from cervical abscess formed by wall of left internal jugular vein.

suspected in any patient who has the characteristic odor of necrotic stomach emanating from the breath or neck wound. A massive leak on barium swallow or with drinking water may represent a significant anastomotic disruption. However, if the patient remains afebrile, and the systemic symptoms resolve after the neck wound is opened, although a protracted course of wound care may be required, the neck wound usually closes spontaneously.

On the other hand, patients with the characteristic odor of necrotic tissue who remain in a toxic and febrile condition most likely have slough of the upper aspect of the stomach and require esophagoscopy and exploration in the operating room. A more difficult clinical decision must be made in patients with a CEGA who have fever approximately 4 to 7 days after operation. In these patients other common causes of postoperative fever such as atelectasis, pneumonia, urinary complications, and other wound complications must be excluded; if no other explanation is found, a barium swallow is obtained and the wound is opened if indicated. However, if cervical crepitus, erythema, fluctuance, or drainage from the cervical incision develops, the neck wound should be opened at the bedside immediately and the patient given water to drink while the wound is observed for obvious evidence of a leak. Exploration of the neck wound at the bedside is done by removing the skin, subcutaneous, and muscular sutures and gently probing the wound to break down loculations. The patient is given water to drink after exposure of the anastomosis. Gentle gauze packing of the wound is then done every 4 to 6 hours, and the patient is given water to drink with each dressing change to facilitate irrigation and cleaning.

A key point in the management of a CEGA leak is institution of early dilation. Patients are given a clear liquid diet for the initial 2 to 3 days after identification of the leak, and a bedside dilation of the CEGA is done with a series of Hurst-Maloney bougies ranging in size from $36 \mathrm{~F}$ to $46 \mathrm{~F}$. Early dilation in the management of CEGA leaks results in earlier closure and improved swallowing. ${ }^{12}$ Dilation may be required in the future, because in one third of patients with an anastomotic leak a cervical anastomotic stricture developed, and patients should be instructed to return promptly for a repeat dilation if dysphagia recurs after discharge from the hospital.

If significant necrosis of the upper stomach is found, there is little option but to take down the anastomosis, return the stomach to the abdomen, resect nonviable tissue, and construct a cervical esophagostomy. After removal of the intrathoracic stomach, the mediastinum is irrigated from above and below with several liters of warm saline solution, 


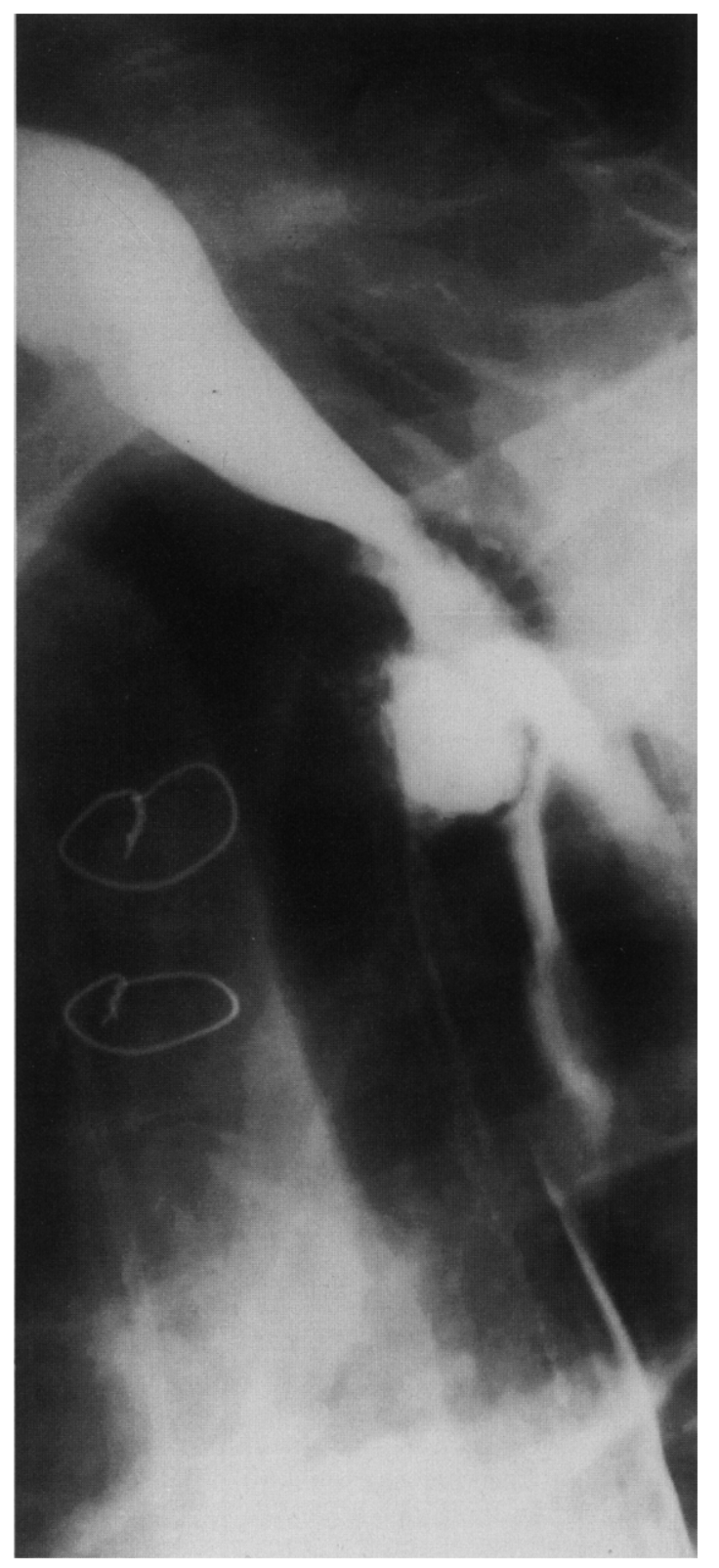

Fig. 4. Contained anterior CEGA leak demonstrated on barium esophagogram 10 days after operation. Extravasated barium abuts posterior membranous trachea. This leak was asymptomatic and was not drained. Nine days later, a tracheoesophagogastric anastomosis fistula developed and patient ultimately died of multisystem organ failure after attempted repair.

and chest tubes are placed as indicated. Once the patient has recovered from this devastating complication, generally several weeks or months later, restoration of alimentary continuity with an intestinal inter-

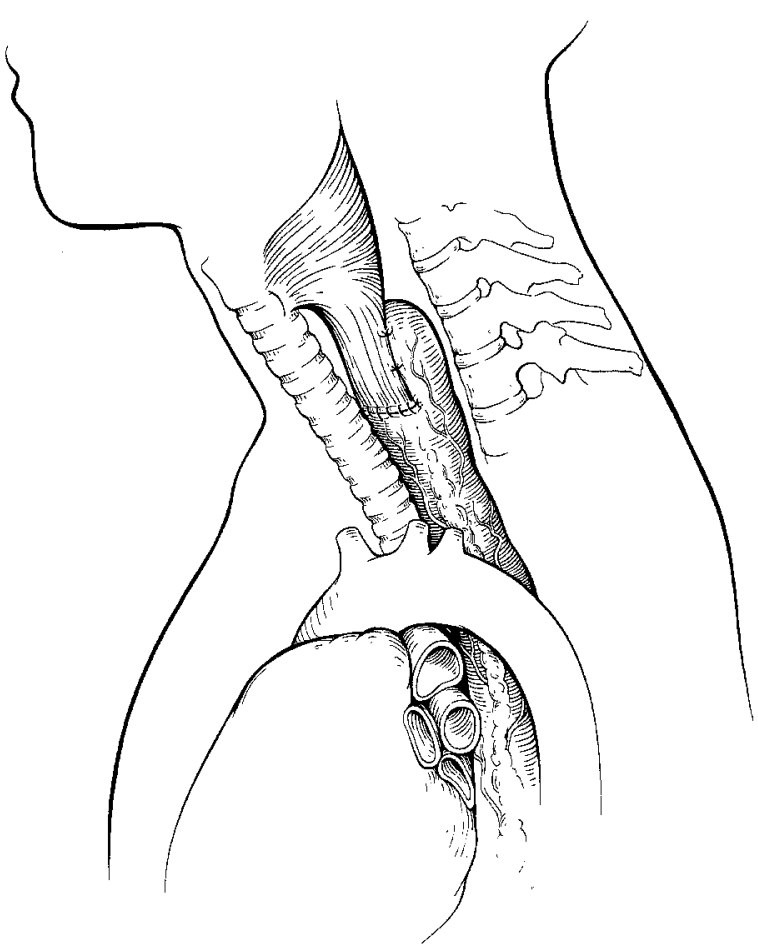

Fig. 5. Currently advocated technique of suspension stitch placement. Two anterior sutures between back of cervical esophagus and adjacent stomach limit tension on esophagogastric anastomosis and prevent needle inoculation of spine, which is inherent in posterior sutures. (Reproduced with modification with permission from Orringer MB. Transhiatal esophagectomy without thoracotomy. In: Orringer MB, Zuidema GD, eds. Shackelford's surgery of the alimentary tract. 3rd ed. Vol. 1. Philadelphia: WB Saunders, 1991.)

position can be done. In patients with cancer, evidence of metastatic disease frequently develops within several months of esophagectomy, and in those patients with cancer who have required takedown of the anastomosis because of anastomotic problems, observation and nutritional support with jejunostomy tube feedings for 6 to 12 months is indicated before reconstructive operation is considered.

THE with CEGA is now an accepted method of esophageal resection and reconstruction. Further refinements in CEGA technique will improve results with this operation even further by reducing the prevalence of anastomotic leak, associated late stricture formation, and the serious complications of gastric tip necrosis and potential neurologic sequelae of cervical spine infection. Ongoing assessment of operative results and particularly postoperative 
complications and their causes provides a logical basis for technical modifications to avert such problems.

\section{REFERENCES}

1. Bolton JS, Ochsner JL, Abdoh AA. Surgical management of esophageal cancer: a decade of change. Ann Thorac Surg 1994;219:475-80.

2. Fok M, Law S, Stipa F, Cheng S, Wong J. A comparison of transhiatal and transthoracic resection for oesophageal carcinoma. Endoscopy 1993;25:660-3.

3. Gelfand GA, Finley RJ, Nelems B, Inculet R, Evans KG, Fradet G. Transhiatal esophagectomy for carcinoma of the esophagus and cardia: experience with 160 cases. Arch Surg 1992;127:1164-7.

4. Griffith JL, Davis JT. A 20-year experience in the surgical treatment of carcinoma of the esophagus and gastric cardia. J THORAC CARDIOVASC SuRg 1980;79:44752.

5. Lam TC, Fok M, Cheng SW, Wong J. Anastomotic complications after esophagectomy for cancer: a comparison of neck and chest anastomoses. J THORAC Cardiovasc Surg 1992;104:395-400.

6. Lee Y, Fujita H, Yamana H, Kakegawa T. Factors affecting leakage following esophageal anastomosis. Surg Today 1994;24:24-9.

7. Orringer MB, Marshall B, Stirling MC. Transhiatal esophagectomy for benign and malignant disease. $\mathrm{J}$ ThORAC Cardiovasc Surg 1993;105:265-76.

8. Pac M, Basoglu A, Kocak H, et al. Transhiatal versus transthoracic esophagectomy for esophageal cancer. J Thorac Cardiovasc SuRg 1993;106:205-9.

9. Postlethwait RW. Complications and death after operations for esophageal carcinoma. J THORAC CARDIOVASC SuRg 1983;85:827-31.

10. Putnam JB Jr, Suell DM, McMurtrey MJ, et al. Comparison of three techniques of esophagectomy within a residency training program. Ann Thorac Surg 1994;57:319-25.

11. Tilanus HW, Hop WC, Langenhorst BL, van Lanschot JJ. Esophagectomy with or without thoracotomy: is there any difference? J THORAC CARDIOVASC SURG 1993;105:898-903.

12. Orringer $\mathrm{MB}$, Lemmer JH. Early dilation in the treatment of esophageal disruption. Ann Thorac Surg 1986;42:536-9.

13. O'Rourke I, Tait N, Bull C, Gebski V, Holland M, Johnson DC. Oesophageal cancer: outcome of modern surgical management. Aust N Z J Surg 1995;65:11-6.

14. Rahamim J, Cham CW. Oesophagogastrectomy for carcinoma of the oesophagus and cardia. Br J Surg 1993;80:1305-9.

15. Goldminc M, Maddern G, LePrise E, Meunier B, Campion JP, Launois B. Oesophagectomy by a transhiatal approach or thoracotomy: a prospective randomized trial. Br J Surg 1993;80:367-70.

16. Katariya K, Harvey JC, Pina E, Beattie EJ. Compli- cations of transhiatal esophagectomy. J Surg Oncol 1994;57:157-63.

17. Zieren HU, Muller JM, Pichlmaier H. Prospective randomized study of one- or two-layer anastomosis following oesophageal resection and cervical oesophagogastrostomy. Br J Surg 1993;80:608-11.

18. Vigneswaran WT, Trastek VF, Pairolero PC, Deschamps C, Daly RC, Allen MS. Transhiatal esophagectomy for carcinoma of the esophagus. Ann Thorac Surg 1993;56:838-44.

19. Jauch KW, Bacha EA, Denecke H, Anthuber M, Schildberg FW. Esophageal carcinoma: prognostic features and comparison between blunt transhiatal dissection and transthoracic resection. Eur J Surg Oncol 1992;18:553-62.

20. Orringer MB, Sloan H. Esophagectomy without thoracotomy. J Thorac Cardiovasc Surg 1978;76:643-54.

21. Orringer MB. Transhiatal esophagectomy without thoracotomy for carcinoma of the esophagus. Ann Surg 1984;200:282.

22. Stone CD, Heitmiller RE. Simplified, standardized technique for cervical esophagogastric anastomosis. Ann Thorac Surg 1994;58:259-61.

\section{Discussion}

Dr. Douglas J. Mathisen (Boston, Mass.). Dr. Iannettoni and his colleagues have been proponents of this technique, the THE, for a long time and have added immeasurably to our understanding of how to perform the operation, deal with complications, and understand the long-term functional results. Their willingness to review, critically analyze, and rigorously report their data should serve as a model for all of us: as we are doing our work we need to continually reevaluate it and refine it. Not only do we benefit from this, but obviously our patients also benefit as well.

I have four questions. Is there any way in the course of the operation that one can identify patients who might be at risk for ischemic injury? Some have suggested fluorescein and some have suggested using $\mathrm{O}_{2}$ oximetry probes to try to identify this problem before complications occur. Have the authors done anything about this or do they have any thoughts about it?

What would be the authors' recommendation if at the time of operation they were worried about the tip of the stomach? I must admit every time I do this the stomach looks pretty beaten up by the time I have pulled it up posteriorly and completed the anastomosis, and I am always a little concerned about it. What would be the authors' indications for doing something or taking the stomach down intraoperatively?

It has always been my suspicion that the biggest problem with ischemic injury and leaks related to a THE, especially with the stomach in the posterior position, is that area bounded by the azygos vein, carina, spine, and aorta, where there is relative constriction of the stomach, and that venous congestion is really the culprit. Do the authors have any thoughts or technical suggestions that might reduce this problem? 
Finally, is it so obvious when one explores the cervical wound that there is necrosis? If not, could the authors explain in greater detail how they try to determine the presence of necrosis?

Dr. Iannettoni. With respect to intraoperative identification of the risk of gastric compromise, when we pass the stomach through the hiatus into the posterior mediastinum and position it in the neck, we try to make this a relatively closed operation. Therefore we do not open the stomach until we have placed the hiatal sutures, tacked the stomach to the diaphragm, and completely closed the abdomen, and we constantly check the tip of the stomach in the neck to make sure that it still appears viable after we have brought it up through the mediastinum.

We have not used oximetry or fluorescein, although we have talked about ways to measure blood supply. It seems that clinical evaluation and inspection of the stomach as we are closing the abdomen and positioning our jejunostomy tube gives us enough time to determine whether the stomach has been damaged with mobilization. Clearly, since we have not been placing the posterior suspension stitches, the stomach appears to have better viability when it is stationed in the neck, and we check it visually about every 5 minutes to make sure that there are no ischemic problems.

The second question related to ischemia identified at the time of operation. If one is concerned about ischemia at the time of operation, one of the things that can be done is to delay the cervical anastomosis, leaving the stomach up in the neck: this has been described but we have never done it in practice. We have tried to do the anastomosis, and usually what we observe is venous congestion of the gastric conduit, which improves with time. If we have a leak, we can control it after operation and treat it at that time.

One of the important technical aspects in placing the stomach in the posterior mediastinum after the esophagus is removed is to be able to pass one's hand easily through the thoracic inlet where the esophagus was, so that the stomach can easily be passed through to the posterior mediastinum. Usually this allows enough room for the stomach to go through and not be constricted. I do agree that it is probably a venous problem most of the time: the stomach, when it does look dusky, still bleeds quite well, but the problem is usually from venous congestion. If the stomach appears to be dusky, then it can be taken down from the posterior mediastinum and assurance made that the thoracic inlet is wide enough by passing one's hand back through this region.

The last question related to the diagnosis and management of postoperative leaks. We open the cervical wounds postoperatively in all of these patients if we suspect a leak or if there is a leak on barium swallow. We place six stitches plus a skin suture, and these stitches are removed at the bedside, the wound is opened, the patient is given water to drink so that we can identify the anastomotic leak, and the wound is packed. Another important aspect in the management of the esophagogastric anastomotic fistula is early dilation before the patient's discharge from the hospital. Most of these leaks close in about 4 days after the leak has been identified; however, when there is a large leak, especially with a gastric tip necrosis, the problem is very obvious. The wound has significant odor to it and constant egress of large amounts of salvia and swallowed fluids. This necessi- tates operative revaluation and intervention to manage the problem of major anastomotic disruption.

Dr. F. Griffith Pearson (Toronto, Ontario, Canada). I wish to make a practical point relating to the recognition of a major degree of gastric necrosis. I am in agreement with what the authors state: if there is a large leak and that terrible putrid odor is detected, one should be suspicious of such necrosis. I have, however, found it useful to do a flexible esophagoscopy in any patient with a significant cervical leak after esophagogastrostomy. The information obtained may be highly instructive and will distinguish between massive necrosis and minor areas of separation and ischemic change. The findings may well modify the decision about management. Furthermore, no more damage is done with flexible endoscopy in these patients than may occur with the patient's swallowing, and the authors do not hesitate to have these patients "irrigate their wounds" by swallowing water.

Not every patient who has a degree of gastric necrosis with odor will need to have the anastomosis taken down. I believe much more can be learned from the observations at esophagoscopy than can ever be determined externally by opening the neck wound and placing a finger down to the anastomosis: one may feel the defect in the anastomosis but one cannot really determine the health of the gastric margins or the change. I strongly recommend use of the flexible endoscope in this circumstance. We all hesitate to use it because we are concerned that blowing air and fluid through the esophagus may be damaging. I have yet to see a patient in whom I thought that such endoscopy added any damage to the preexisting problem. It may be that these authors do use flexible endoscopy in this evaluation, and I would be interested to hear a reply.

Dr. Iannettoni. We do not routinely use the endoscope in patients with CEGA leaks unless there is suspicion of significant disruption or obstruction. One point I neglected to bring out is that these patients, even after the wound was opened, still remained in a toxic condition, and I think this is a key feature. After the wound was opened, defervescence occurred in the majority of patients quite nicely and the conditions improved. However, patients with a major disruption of the cervical anastomotosis continued to have fever and sepsis and were in a persistently toxic condition after conservative treatment. These patients all went to the operating room for evaluation, which did start with esophagoscopy.

Dr. Darrock Moores (Albany, N.Y.). Catastrophic complications associated with esophagectomy and gut interposition are usually a result of poor blood supply in the interposed segment. I have found dopamine in the dose of $3 \mu \mathrm{g}$ or less to be valuable. Dopamine in this dose improves splanchnic circulation and helps with perfusion of the gut segment. We start the dopamine administration in the operating room before operation and continue it for 72 hours after operation. In addition to using dopamine, we pay particular attention to keeping the patients warm and as close to normothermic as possible throughout the operative period. We use a heating blanket and a Bear Hugger warmer (Augustine Medical, Inc., Eden Prairie, Minn.). We also warm the patients' intravenous fluids and inspired gases. We believe that the combination of dopamine and normothermia helps with maintaining gut perfusion. 